\title{
Phthalates in Food and Medical Devices
}

\author{
Karen Chou PhD a \\ Robert O. Wright $M D M P H^{\mathrm{b}}$
}

\begin{abstract}
a Associate Professor of Toxicology, Michigan State University Department of Animal Science Environmental Science and Policy Program, Research Associate, Harvard School of Public Health

b Assistant Professor of Environmental Health, Harvard School of Public Health Assistant Professor of Pediatrics and Internal Medicine, Harvard Medical School, Boston, Mass
\end{abstract}

\section{nomk}

American College of Medical Toxicology, www.acmt.net

REPRINTED FROM WWW.ACMT.NET

Funded by the Agency for Toxic Substances and Disease Registry Cooperative Agreement Number U61/ATU374416-01, Program Capacity to Conduct Environmental Medicine and Health Education Activities.

Produced in collaboration with the Association of Occupational and Environmental Clinics and the Pediatric Environmental Health Specialty Unit Program.

\section{Q. I have heard about phthalates in the news. What are they?}

A. Phthalates are important industrial chemicals used in a wide variety of plastic products. (Figure1). They are structurally related compounds used as plasticizers in a broad range of products. Industrially, phthalates confer flexibility, pliability and elasticity to plastics by allowing the polymer molecules to slide against each other. Frequently used phthalate plasticizers include di (2-ethylhexyl) phthalate (DEHP), diisodecyl phthalate (DIDP), diisononyl phthalate (DINP), di-methyl phthalate (DMP), di-ethyl phthalate (DEP), di-n-butylphthalate (DBP), buytylbenzylphthalate (BBP), and polyethylene terephthalates (PET) which are used as intermolecular lubricants and have a tendency to leach out of the plastic matrix.

Since the first application as plasticizers in the 1930s, phthalates have become one of the most widely spread contaminants in the modern world. About 8 billion pounds of phthalate esters are consumed globally every year (Cadogan and Howick 1996) (Mannsville Chemical Products Corporation 1999). Unlike persistent organic pollutants (organochlorine pesticides like DDT), phthalates and their metabolites do not accumulate in the environment and have a short-half life in living organisms (see below). They are nonetheless a constant presence in all human exposure pathways. Monoester metabolites are detected in 90-100 percent of urine samples from women and men of general populations (Duty et al., 2005a; Hoppin et al., 2002; Kato et al., 2005; Swan et al., 2005).

\section{Q. How much do we know about the toxicity of phthalates in the environment?}

A. Results from laboratory animal studies demonstrate developmental and reproductive effects of some of the commonly used phthalates in commercial products, even at dosages close to the potential exposure levels found in the environment. Other effects observed in laboratory animals are allergic reactions of the respiratory system and tumor formation, although scientists do not agree whether phthalates could also induce tumors in human, and there is no evidence to support that phthalates cause cancer in humans. 


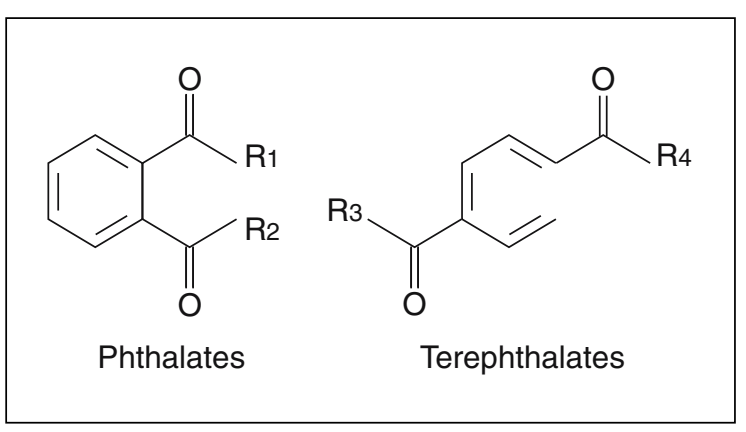

Figure 1. Common structures of phthalates $R_{x}$-alkyl, alkenyl, or aryl groups

\section{Q. What can phthalates do to my children?}

A. There is limited evidence for adverse health effects of phthalates in children. Animal data suggest potential reproductive and allergic effects of phthalates, including asthma, changes in hormonal balance, and fertility impairments. Evidence for direct health effects in humans is lacking, due to a paucity of research. The potential health effects described in the following sections should be taken into consideration when taking measures to protect children's health.

\section{Q. What are the potential health effects of phthalates in general?}

A. Research suggests three general types of potential health concerns of phthalate exposure: developmental and reproductive toxicity, allergy/asthma, and carcinogenicity. In animals, phthalates interfere with testicular function, decrease sperm motility/production, and alter the hormone profile in both male and female animals. Among all phthalates tested, DEHP appears to be the most potent one. Existing human data have provided evidence for the reproductive effects by analyzing phthalates in urine samples.

A handful of other studies have also associated allergy and asthma with exposure to MBP, MEP, DEHP and BBzP. Some of these effects appear to be chemical-structure specific and dependent on the timing and route of exposure. More detailed information from research data is provided in the following sections.

\section{Q. What are the potential reproductive effects of phthalates?}

A. Only limited information on reproductive effects of phthalates is available. Data in DEHP exposed male workers indicate that time to pregnancy is not prolonged with paternal exposure to DEHP (Modigh et al., 2002), although time-to-pregnancy is not considered a sensitive measurement of fertility. In contrast, a more recent study found a significant inverse association between concentrations of urinary $\mathrm{MBzP}$ and serum $\mathrm{FSH}$, a reproductive hormone (Duty et al., 2005b). There is also an interaction between high urinary MBP and the environmental toxin, polychlorinated biphenyls (PCBs) with regard to sperm motility (Hauser et al., 2005) such that joint exposure to MBP and PCB's multiplicatively decreased motility. In a study of healthy Swedish men, subjects within the highest quartile for MEP had fewer motile sperm and lower concentrations of the reproductive hormone LH in the serum; no effect was seen for MBP (Jonsson et al., 2005). In other studies, high urinary phthalate monoesters are associated with reduced sperm counts, low sperm motility and low DNA integrity (Duty et al., 2003a; Duty et al., 2003b). All together, these reports raise concerns over the reproductive toxicity of phthalates in males.

Data on reproductive effects of phthalates in women are relatively scarce (Jung Koo and Mu Lee, 2005). A case control study demonstrated an association between endometriosis and elevated concentrations of plasma DEHP (Cobellis et al., 2003). Another study demonstrated an association between the concentrations of DEHP and MEHP in cord blood and shortened gestation age (Latini et al., 2003). In addition, in a study in India, premature breast development in girls of 8 years of age was associated with high concentrations of serum DEHP and MEHP (Colon et al., 2000).

In animals, exposure to moderate doses of DEHP and BBP result in changes in reproductive hormone levels in males (Akingbemi et al., 2004; Akingbemi et al., 2001; Kurahashi et al., 2005; Ljungvall et al., 2005; Wang et al., 2005) and changes in estrous cycles in females (Davis et al., 1994; Lovekamp Swan and Davis, 2003; O'Connor et al., 2002).

\section{Q. Can phthalate exposure cause asthma and allergy?}

A. Results from a few epidemiological studies suggest possible associations between inhalational exposure to certain phthalate analogs and upper airway irritation and asthma. The outcome is not only chemical-structure (congener) dependent, but also dosage and exposure-route specific.

In a case of office building related illness, metabolites from polyvinyl chloride floor coating of a damp office building was identified as the cause of inflammatory nasal mucosal responses of office workers (Walinder et al., 2001). In a case-control study, the presence of BBzP in indoor dust was implicated in rhinitis and eczema in children, while the presence of DEHP in dust was associated with asthma (Bornehag et al., 2004). Data from the Third National Health and Nutrition Examination Survey (NHANES III) showed an association between decreased pulmonary function and urinary concentrations of MBP and MEP (Hoppin et al., 2004). The measures of urinary metabolites, although useful markers for total phthalate uptake, are not reliable estimates for inhalation exposure and inhaled vs ingested doses cannot be distinguished. This may explain differences in effects in some studies if pulmonary effects are primarily from inhalation. 
Animal and in vitro studies provide some support for potential allergic reactions observed in human studies. Inhalation of MEHP in mice induces lower airway irritation, rapid shallow breathing and elevated macrophage in bronchoalveolar lavage (Larsen et al., 2004). Increases in the rate of phagocytosis after exposure to DEHP has been demonstrated in alveolar macrophages (Bally et al., 1980). Several phthalates and metabolites illicit inflammatory response such as producing cytokine IL- 6 and IL-8 expression in human and animal cells (Jepsen et al., 2004; Yamashita et al., 2005). These findings suggest that medical devices may induce respiratory inflammation and heighten the needs for additional studies on phthalates related inflammatory responses. They are particularly concerning given the widespread use of phthalates in medical devices and equipment (Gourlay et al., 2001).

\section{Q. Do phthalates cause cancer?}

A. Carcinogenicity of phthalates in human has yet to be demonstrated. Reports on phthalate induced liver tumors in rodents were first published in the early 1980's. Subsequent studies have demonstrated elevated incidence of testicular tumor and renal cysts in laboratory animals (Kluwe, 1986; Voss et al., 2005), but phthalates are not genotoxic, nor do they induce mutations in animals or in in-vitro testing systems. Phthalates have been shown to induce liver enlargement and proliferation of hepatic peroxisomes in laboratory rodents (Howarth et al., 2001). Testicular tumors have been described in animals as well (Astill et al., 1996; Kaufmann et al., 2002; Voss et al., 2005). Currently, there is no evidence for phthalate-induced tumors in humans. There has long been a debate among scientists over the appropriateness of applying the data of carcinogenesis of phthalates to rodents in assessing their effects in human. For example, peroxisomal proliferation is believed to be the underlying mode of action for the tumors observed in rats and mice (Kaufmann et al., 2002). However, there is a lack of peroxisomal proliferation of human hepatocytes in vitro. In the absence of evidence for elevated cancer incidence in exposed human populations, it is possible that peroxisome proliferation related liver injury and the subsequent hepatic tumor formation in rats and mice are not relevant to a health risk in humans. Other researchers however argue for an alternative mechanism where peroxisome proliferation is not a prerequisite of tumor formation; thus the debate over the phthalate carcinogenicity in human continues (Lai, 2004).

\section{Q. How are people exposed to phthalates?}

A. In the modern living environment, humans and animals are constantly exposed to phthalates through numerous pathways, including food, ambient air, indoor air, drinking water, soil, toys, aerosol sprays, cosmetics, automobile interior, pharmaceutical products, and medical devices (Latini et al., 2004b). For the general, non-occupationally and non-medical device exposed population, ingestion of contaminated food and inhalation of household aerosol sprays and fragranced personal care products are the major routes of exposure.

DEHP, the most frequently used plasticizer in PVC products, is present in toys, intravenous tubing, blood transfusion bags, plastic wraps for food, shower curtains, floors and walls. DBP is often used as softener in PVC resins, while BBP is a frequently used ingredient in adhesive formulations in flooring, paints, coatings and printing inks. DEP is used in chip-resistant nail polish. All three phthalates with short alkyl-side-chains, DMP, DEP and DBP, are used as fixatives in long-lasting fragrances, perfumes, hairsprays, and deodorants. Phthalates are also common components of lubricants, weather stripping, and safety glass.

In recent years, cellulose acetate phthalate has been used as a coating or binding matrix in enteric tablets for time-and pH-controlled drug release (Amorim and Ferreira, 2001; Guzman et al., 1996; Kim et al., 2003; Makhija and Vavia, 2003). Medical procedures that use devices made from flexible vinyl component, such as storage bags and tubing in ventilation, blood transfusion and dialysis devices introduce significant amounts of phthalates to patients.

While adults in the general population are exposed to phthalates through air, food/food containers, cosmetics and personal hygienic products, infants and children have additional exposure through mouthing behaviors on toys and other plastic products. Other phthalates detected in children's products include DIDP, DINP, DIOP, and DnNP (Latini et al., 2004b).

The estimated overall non-occupational, non-medical device exposure range from 3-41 microg/kg bw/day for DEHP, 10 microg/kg bw/day for DBP, 2 microg/kg bw/day for BBP, and 1.9-7 microg/kg/day for DBP (Doull et al., 1999; Jung Koo and Mu Lee, 2005; Kavlock et al., 2002a; Kavlock et al., 2002b).

Individual variations in living environment, use of phthalate containing aerosol spray and cosmetics, and genetic factors all contribute to the large differences in exposure and metabolism of phthalates in the population (Duty et al., 2005a). Elevated urinary MEP concentrations (median, $265 \mathrm{ng} / \mathrm{ml}$ ) have been observed in men within 48 hours after using colognes, when compared with non-cologne users (median, $108 \mathrm{ng} / \mathrm{ml}$ ). Use of aftershave is also associated with an increase in urinary MEP, from $133 \mathrm{ng} / \mathrm{ml}$ in non-users to $266 \mathrm{ng} / \mathrm{ml}$ in users.

\section{Q. How do phthalates enter the environment?}

A. Ambient Air:

Most phthalates enter the environment through smokestack emissions and vaporization from plastic products. In the ambient air, the concentration of phthalates in the vapor phase is unlikely to exceed $0.1 \mathrm{microg} / \mathrm{m}^{3}$, although concentrations above $1.0 \mathrm{microg} / \mathrm{m}^{3}$ have been recorded in areas surrounding phthalate and plastic factories (Liss et al., 1985). 
Indoor Air:

The major sources of phthalates in indoor air are air fresheners, cosmetic products, fabrics, flooring and other building materials, therefore, large differences in indoor air among households are expected. In general, the indoor air phthalate concentration, contributed mostly by phthalate residues adsorbed to suspended particles, is several folds higher than that in the outdoor air. The total concentration of inhalable phthalates may range from less than $1 \mathrm{microg} / \mathrm{m}^{3}$ to over $10 \mathrm{microg} / \mathrm{m}^{3}$.

As for variations of different congeners in the environment, the air samples collected in New York City are dominated by DEP, while those collected in Krakow, Poland, are dominated by DBP (Adibi et al., 2003). In particles of indoor air studied in Norway, DEHP accounts for greater than 50\% of total phthalates (Oie et al., 1997).

\section{Surface Water:}

In aqueous solutions, phthalates are essentially insoluble, except those with short alkyl side chains. Therefore, the concentration in surface and ground water are usually less than 10 ppb and rarely exceed 10 ppm (Hites, 1973; Lopez Roldan et al., 2004; Mihovec Grdic et al., 2002).

\section{Drinking Water:}

The U.S. EPA has established an MCL of $6 \mathrm{ppb}$ for DEHP for drinking water. In municipal drinking water, concentrations range from less than 1 ppb to 3 ppb (Luks Betlej et al., 2001). Increases in phthalate content have been reported in drinking water stored in polyethylene bottles (Criado et al., 2005).

\section{Q. How do phthalates get into food?}

A. Raw agricultural products contain a minimum amount of phthalates. Phthalates typically are unintentionally added to food during processing and packaging. Total phthalates in the muscle of livestock and raw milk (120-280 microg/kg) rarely exceed $500 \mathrm{microg} / \mathrm{kg}$ (Casajuana and Lacorte, 2004; Rhind et al., 2005; Sharman et al., 1994). However, elevated concentrations of phthalates, up to 53,000 microg $/ \mathrm{kg}$, have been detected in food items on the market likely contaminated by processing and packaging (Castle et al., 1989).

Direct contact with phthalate containing surfaces of processing equipment and packaging material is a major source of phthalates in the diet, especially in food items of high lipid contents. Tsumura et. al. (2001a) demonstrated an increase in DEHP in chicken, from $80 \mathrm{microg} / \mathrm{kg}$ precooking to $13,100 \mathrm{microg} / \mathrm{kg}$ after frying in a Teflon coated pan, and further to $16,900 \mathrm{microg} / \mathrm{kg}$ after packing. Printing ink on wrapping films is another source of phthalates in confectionary and snack products (Castle et al., 1988). Heating food in the ready-to-eat packages greatly facilitates phthalate migration from packaging materials to food.

In dairy products, greater than $80 \%$ of total concentrations, ranging from 50 to 200 microg/kg in commercial milk, may be originated from milking equipment(Casajuana and Lacorte, 2004; Castle et al., 1990). Additional processing, packaging, and condensation can lead to 5-100 fold increases in DEHP concentrations in cream and cheese products (Casajuana and Lacorte, 2004; Mortensen et al., 2005; Petersen, 1991; Sharman et al., 1994). Up to 11,100 microg/ $\mathrm{kg}$ of DEHP in food can be attributed to leaching from PVC gloves used during food preparation (Tsumura et al., 2001a; Tsumura et al., 2001b). Analysis of meals prepared in three hospitals in Japan revealed that the use of gloves alone could contribute to 600 microg of DEHP to daily dietary exposure. Daily meals from these hospitals, on the average, contain 160 microg DEHP, 12.5 microg DEHA, 4.7 microg DINP, and 3.4 microg BBP.

\section{Q. How much phthalate is usually present in milk or infant formula?}

A. Phthalates in infant formula and breast milk are of special concerns because of the vulnerability of infants and young children. In general, the concentration of DEHP and DBP in infant formula, 34-281 microg/ $\mathrm{kg}$, is about the same as that in cow's milk, while concentrations of phthalate monoesters in human breast milk is considerably higher (Dostal et al., 1987; Mortensen et al., 2005; Sharman et al., 1994). The composition of phthalates in breast milk is similar to that detected in adipose tissue (Calafat et al., 2004; Mortensen et al., 2005; Swedish, 1998). A portion of the detected MEP and MBP can be attributed to leaching from breast pumps (Mortensen et al., 2005). The estimated upper maximum of infant exposure is $13 \mathrm{microg} / \mathrm{kg}$ bw/day from infant formula and $21 \mathrm{microg} / \mathrm{kg}$ bw from breast feeding (Latini et al., 2004a).

\section{Q. Should I be concerned about exposure from Medical Devices?}

A. Polyvinyl chloride is one of the most frequently used materials in medical devices. Phthalates leached from these devices are a direct source of exposure in patients. These exposures are well documented and are a major concern of the medical community (Karle et al., 1997). Although it is not clear whether the amount of exposure from medical devices pose health risks to patients, it is clear that exposure occurs. The amount of exposure to DEHP varies significantly between hospitals. Empirical data, although limited, have demonstrated a positive associations between the magnitude of exposure and the use of PVC containing tubing, catheters, and gloves (Green et al., 2005; Tsumura et al., 2001b). FDA has judged a tolerable intake (TI) value of $0.6 \mathrm{mg} / \mathrm{kg} /$ day for DEHP (McKee et al., 2004). Many medical procedures in current practice could lead to exposure levels approaching or exceeding the TI. For adults, the estimated exposure to DEHP from 63 units of blood transfusions is $8.5 \mathrm{mg} / \mathrm{kg} /$ day and from hemodialysis, $0.36 \mathrm{mg} / \mathrm{kg} /$ day. Keep in mind that the exposure from these procedures could be incidental for some patients, but frequent and long-term for others. 
For neonates, the 95\% upper bound estimate of exposure to DEHP from total parenteral nutrition (TPN) administration is $2.5 \mathrm{mg} / \mathrm{kg} /$ day and from extracorporeal membrane oxygenation (ECMO), $14 \mathrm{mg} / \mathrm{kg} /$ day (FDA, 2001; Jaeger et al., 2005). A 4-hour dialysis estimation on average is greater than $1 \mathrm{mg} / \mathrm{kg}$ phthalate, with the maximum estimates greater than $2 \mathrm{mg} / \mathrm{kg}$ (Faouzi et al., 1999). For preterm neonates requiring TPN and additional therapy, such as sedation or blood products, the total estimated exposure is $10-20 \mathrm{mg} /$ day (Loff et al., 2002). Other types of medical procedures that could also result in excessive amounts of exposure are illustrated in the FDA Public Health Notification of July 12, 2002 (Feigal, 2002).

New mechanical designs, new plastics, leach resistant coatings, and modifying the conditions of medical procedures are all being studied in order to decrease patient exposure (Hogman et al., 1991; Shimizu et al., 1989). For ECMO, a $40 \%$ decrease in patient exposure can be achieved by decreasing the surface area of ECMO circuit (Karle et al., 1997). The practice of freezing plasma soon after collection effectively minimizes leaching. It is well documented that addition of anticoagulant acid citrate dextrose or citrate phosphate dextrose in blood significantly reduces the leaching of phthalates from PVC bags, so does covalently coating the inner tubing or PVC lining with heparin (Haishima et al., 2004). Ionic coating with heparin, however, is not effective.

\section{Q. My child frequent chews on toys. Can this lead to phthalate exposure?}

A. Infants and toddlers can be exposed to significant amounts of phthalates from chewing on pacifiers, teething rings, and toys. Various phthalates have been used in commercial products for children. DINP is the principal plasticizer in plastic toys made for infants and toddlers. Exposure from mouthing differs significantly, depending on the vigor, frequency and length of mouthing. Among three age groups, 6-11 months, 12-23 months, and 24-36 months, the estimate for the 12-23 months group is the highest; 0.08 microg $/ \mathrm{kg}$ BW per day (95\% confidence interval, $0.04-0.14$ microg/kg per day) (Babich et al., 2004). Estimates by other researchers, however, are 2 to 3 magnitudes higher than even this, ranging from 5.7 (95th percentile 94.3) microg/kg/day by Wilkinson and Lamb (Wilkinson and Lamb, 1999) to $21.4 \mathrm{microg} / \mathrm{kg} /$ day by Sugita et al. (Sugita et al., 2003). All these estimates, however, are at least one magnitude lower than FDA's Tolerable Intake for DEHP (600 microg/kg/day).

\section{Q. If phthalates are so common, how much exposure does my child get and how much do I get?}

A. Phthalate exposure may result from ingestion, inhalation, and dermal contact. In children, mouthing toys accounts for a significant portion of exposure, ranging from less than
$1 \mathrm{microg} / \mathrm{kg}$ body weight (BW) to over $90 \mathrm{microg} / \mathrm{kg}$ BW per day (Babich et al., 2004; Sugita et al., 2003; Wilkinson and Lamb, 1999). Estimated total intake is about 410 microgg $/ \mathrm{kg}$ BW per day for children of 0.5 to 3 years of age and 20 microg/kg BW per day for adults (European Chemicals Risk Assessment Report, 2001). Occupational exposure up to 1100 microgg/kg bw/day has been documented.

\section{Q. Has the exposure to DEHP, the most potent phthalate, decreased in the recent years?}

A. DEHP was widely used for pacifiers and toys in the 1970's and early 1980's. Since the recognition of its toxicity and the subsequent restriction of its use in children's products, a general trend of decreased exposure in young children in the past two decades has occurred.

Changes in exposure to phthalates in the U.S. population over time are shown in the National Report on Human Exposure to Environmental Chemicals, in which data on DEHP are available in the Second Report and the Third Report, which cover the years 1999-2000 and 2000-2001, respectively (CDC, 2005). The survey in each Report includes more than 2,500 individuals age 6 and above. Based on this data, exposure to DEHP among children 6-11 years decreased over this time period; the geometric means of urinary metabolite MEHP decreased from $5.12 \mathrm{microg} / \mathrm{L}$ in 1999-2000 to $4.44 \mathrm{microg} / \mathrm{L}$ in 2000-2001 (CDC, 2005). However, in the overall population, there was an approximate $29 \%$ increase in exposure between the two Reports, from 3.43 to 4.27 microg/ L. Exposure in children 6-11 years old remains higher than that in teenagers and adults.

\section{Q. Do phthalate chemicals enter the environment and never go away, like DDT?}

A. The half-lives of phthalates in the environment are relatively short; in general, they spend hours in the atmosphere and months in soil. However, phthalates adsorbed to soil and sediments can persist in the environment for years. Phthalates do not bioaccumulate in the food chain, nor do they bioconcentrate in living organisms. Concentrations of phthalates in the body therefore reflect recent exposure.

\section{Q. How does my body get rid of phthalates?}

A. The metabolic breakdown of phthalates is not fully understood. Production of monoester metabolites by esterases is the common pathway for the frequently used phthalate ester plasticizers. Phthalates are metabolized in the liver and excreted mainly in urine.

The metabolic pathways and distribution of DEHP in the body are qualitatively similar to those of DINP. After intravenous exposure, a higher portion of the parent compound DEHP is detected in patients than after oral exposure (Sjoberg et al., 1985c). Neonates and young children are considered high-risk population because of a relatively high 
amount of absorption and low rate of excretion, when compared with the adults. Pre-term newborns are especially vulnerable; their slow rate of excretion of monoester metabolite MEHP has been documented (Roth et al., 1988; Sjoberg et al., 1985a; Sjoberg et al., 1985b). Similarity, most of the DINP and metabolites are excreted in the urine within 24 hours of exposure. Only a small amount is excreted in the feces. There is no evidence for long-term accumulation of DINP or metabolites in the body.

\section{Q. When I am pregnant, will my baby be exposed to the phthalates in the food I eat or in the air I breathe?}

A. Yes, phthalates do cross the placenta during pregnancy and expose babies. During pregnancy, significant amount of phthalates and their metabolites are transferred to the fetus (Calafat et al., 2004; Fennell et al., 2004; Saillenfait et al., 1998). Human placenta is not an effective barrier for fetal exposure to phthalates. The cord plasma concentration of DEHP in human fetus $(2.05+/-1.47 \mathrm{microg} / \mathrm{ml})$ is almost twice as that in the maternal plasma $(1.15+/-0.81$ microg/ $\mathrm{ml}$ ), while equal concentrations of MEHP in maternal and fetal plasma are observed, $0.68+/-1.03 \mathrm{microg} / \mathrm{ml}$ and $0.68+/-0.85 \mathrm{microg} / \mathrm{ml}$, respectively (Latini et al., 2003). While exposure will occur, the dose-response of adverse health effects is yet to clarified.

\section{Q. Are phthalates dangerous to my unborn child?}

A. In spite of the well-documented gender-specific high exposure in women, particularly in teenagers and women of reproductive age, data on the development toxicity of phthalates is scarce (Jung Koo and Mu Lee, 2005). A single study of maternal-infant pairs suggests that some of the commonly used phthalates may be developmental toxicants in human fetus (Swan et al., 2005). In this study, concentrations of some phthalate metabolites were inversely related to anogenital distance (AGD), which, in turn, was significantly correlated with penile volume and the proportion of boys with incomplete testicular descent (Swan et al., 2005).

Animal data indicate that phthalates interfere with the metabolic balance of estrogen and testosterone. These endocrine changes underlie the toxicity of phthalates during fetal and neonatal development. In animals, gestational and lactational exposure to DEHP increases neonatal mortality, decreases anogenital distance (AGD), causes nipple retention in male offspring. Developmental effects also include epididymal agenesis, underdevelopment of male accessory glands, undescended testes, incomplete preputial separation, dorsolateral prostate, seminal vesicle agenesis, lower weight testes, and low sperm production (Jarfelt et al., 2005; Moore et al., 2001). Female specific effects include increases in AGD and decreases in ovary weight (Nagao et al., 2000). In addition, inhibitory effects on the development of a dimorphic central nervous system were also observed in male offspring after gestational and lactational exposure to either DEHP and DBP (Moore et al., 2001; Wine et al., 1997). While more research in human is needed, there is evidence from animal studies that points to developmental abnormalities resulting from maternal exposure.

\section{Q. Can phthalate exposure prevent me from becoming pregnant?}

A. In animal studies, infertility has been observed among male offspring after maternal exposure to high doses of phthalates. The effective dosages are usually one or two magnitude higher than human exposure in the environment (Foster et al., 2000; Waterman et al., 2000). In humans, exposure to the environmental and dietary levels of phthalates is unlikely to cause high incidences of infertility in the general population. Subtle effects on hormonal balance, sperm production and sperm motility in men, as those observed in human studies, could influence fertility. In women, phthalates have also been associated with endometriosis, which can be a cause of infertility (Cobellis et al., 2003). The existing data from human studies, however, is far from conclusive (Duty et al., 2005b; Hauser et al., 2005; Modigh et al., 2002; Rozati et al., 2002).

\section{Q. What can I do to decrease exposure to phthalates?}

A. Because phthalates are used in plastic products and such products are ubiquitous, limiting exposure can be challenging. Contaminated food, scented cosmetics, personal care products, and household aerosol sprays contribute to most of the phthalate exposure in the general population. Foods prepackaged in plastics (sliced cheese, plastic milk cartons etc) likely have higher phthalate concentrations than products not individually wrapped or packaged in non-plastic containers. Fresh vegetables, as opposed to frozen vegetables or highly processed products, tend to contain less phthalates. It is important to be aware that many paper products on today's market are coated with plastic films, which contain phthalates. Use of non-plastic containers for long-term food storage, preventing direct contact of hot food or beverage with phthalate-containing-plastic surface, avoid heating food in plastic containers, and minimize consumption of highly processed food could decrease significant amounts of exposure.

Limiting the use of old teething rings, pacifiers, bottles, railings, crib/playpen bumpers, and plastic books manufactured in the 1980s and before could decrease the exposure in infants and young children. Another major source of exposure comes from vapors of cosmetics, personal care products, and household aerosol spray, such as perfume, nail polish, hair spray, aftershave, and air fresheners. Increasing air exchange and ventilation is another measure one may take to decrease exposure to vapors from household products. 


\section{SUMMARY}

Phthalates are ubiquitous environmental chemicals with a broad range of potential adverse health effects. Exposure pathways include air, water, packaged food and household products. Biological effects include disruption of the balance of sex hormones, allergic reactions, and enzyme inhibition. Carcinogenicity is seen in animals. In human studies, phthalates have been associated with poorer sperm quality, the symptomatology of asthma, and shortened AGD. Given the widespread use of phthalates in industrialized countries, further research, particularly on birth outcomes, endocrine disruption and child development are greatly needed.

\section{ABBREVIATIONS:}

\begin{tabular}{|c|c|}
\hline BBP: & Butyl benzyl phthalate \\
\hline BiBP: & Butyl isobutyl phthalate \\
\hline BBzP: & Butyl benzyl phthalate \\
\hline BW: & Body Weight \\
\hline DBP: & Dibutyl phthalate \\
\hline DEHP: & Di (2-ethylhexyl) phthalate \\
\hline DEP: & Diethyl phthalate \\
\hline DiDP: & Di(isodecyl) phthalate \\
\hline DINP: & Diisononyl phthalate \\
\hline DIOP: & Diisooctyl phthalate \\
\hline DiBP: & Di(isobutyl) phthalate \\
\hline DMP: & Dimethyl-phthalate \\
\hline DnNP: & Di-n-nonyl phthalate \\
\hline DnOP: & Di-n-octyl phthalate \\
\hline ECMO: & Extracorporeal membrane oxygenation \\
\hline GIT: & Gastro-intestinal tract \\
\hline IT: & Tolerable intake \\
\hline MBP: & Mono-n-butyl phthalate \\
\hline MBzP: & Monobenzyl phthalate \\
\hline MCL: & Maximum Contaminant Level \\
\hline MCPP: & Mono-3-carboxypropyl phthalate \\
\hline MEHP: & Monoethylhexyl phthalate \\
\hline MEP: & Monoethyl phthalate \\
\hline MEHHP: & Mono-2-ethyl-5-hydroxyhexyl phthalate \\
\hline MEOHP: & Mono-2-ethyl-5-oxohexyl phthalate \\
\hline MiBP: & Monoisobutyl phthalate \\
\hline MMP: & Monomethyl phthalate \\
\hline TPN: & Total parenteral nutrition \\
\hline
\end{tabular}

\section{REFERENCES}

Adibi JJ, Perera FP, Jedrychowski W, Camann DE, Barr D, Jacek R, and Whyatt RM. Prenatal exposures to phthalates among women in New York City and Krakow, Poland. 2003; Environ Health Perspect 111, 1719-1722.

Akingbemi BT, Ge R, Klinefelter GR, Zirkin BR, and Hardy MP. Phthalate-induced Leydig cell hyperplasia is associated with multiple endocrine disturbances. 2004; Proc Natl Acad Sci USA 101:775-780.

Akingbemi BT, Youker RT, Sottas CM, Ge R, Katz E, Klinefelter GR, Zirkin BR, and Hardy MP. Modulation of rat Leydig cell steroidogenic function by di(2-ethylhexyl)phthalate. 2001;Biol Reprod 65:1252-1259.

Amorim MJ, and Ferreira JP. Microparticles for delivering therapeutic peptides and proteins to the lumen of the small intestine. 2001; Eur J Pharm Biopharm 52:39-44.

Babich MA, Chen SB, GreeneMA, Kiss CT, Porter WK, Smith TP, Wind ML, and Zamula WW. Risk assessment of oral exposure to diisononyl phthalate from children's products.

2004; Regul Toxicol Pharmacol 40:151-167.

Bally MB, Opheim DJ, and Shertzer HG. Di-(2-ethylhexyl) phthalate enhances the release of lysosomal enzymes from alveolar macrophages during phagocytosis. 1980; Toxicology 18:49-60.

Bornehag CG, Sundell J, Weschler CJ, Sigsgaard T, Lundgren B, Hasselgren M, and Hagerhed Engman L. The association between asthma and allergic symptoms in children and phthalates in house dust: a nested case-control study. 2004;Environ Health Perspect 112:1393-1397.

Calafat AM, Slakman AR, Silva MJ, Herbert AR. and Needham LL. (2004). Automated solid phase extraction and quantitative analysis of human milk for 13 phthalate metabolites. 2004; J Chromatogr B Analyt Technol Biomed Life Sci 805:49-56

Casajuana, N., and Lacorte, S. (2004). New methodology for the determination of phthalate esters, bisphenol A, bisphenol A diglycidyl ether, and nonylphenol in commercial whole milk samples. 2004; / Agric Food Chem 52:3702-3707.

Castle L, Gilbert J, and Eklund T. Migration of plasticizer from poly(vinyl chloride) milk tubing. 1990;Food Addit Contam 7:591-596.

Castle L, Mayo A, and Gilbert J. Migration of plasticizers from printing inks into foods. 1989; Food Addit Contam 6:437-443.

Castle L, Mercer AJ, Startin JR, and Gilbert J. Migration from plasticized films into foods. 3. Migration of phthalate, sebacate, citrate and phosphate esters from films used for retail food packaging. 1988; Food Addit Contam 5:9-20.

CDC, N. C. f. E. H. Third natnal report on human exposure to environmental chemcials, N. C. f. E. H. Division of Laboratory Sciences, Centers for Disease Control and Prevention, Department of Health and Human Services, ed. 2005.

Cobellis L, Latini G, De Felice C, Razzi S, Paris I, Ruggieri F, Mazzeo P, and Petraglia F. High plasma concentrations of 
di-(2-ethylhexyl)-phthalate in women with endometriosis.

2003; Hum Reprod 18:1512-1515.

Colon I, Caro D, Bourdony CJ, and Rosario O. Identification of phthalate esters in the serum of young Puerto Rican girls with premature breast development. 2000;Environ Health Perspect 108:895-900.

Criado, M. V., Fernandez Pinto, V. E., Badessari, A., and Cabral, D.. Conditions that regulate the growth of moulds inoculated into bottled mineral water. 2005; Int J Food Microbiol 99:343-349.

Davis BJ, Maronpot RR, and Heindel JJ. Di-(2-ethylhexyl) phthalate suppresses estradiol and ovulation in cycling rats. 1994; Toxicol Appl Pharmacol 128:216-223.

Dostal LA, Weaver RP, and Schwetz BA. Transfer of di(2ethylhexyl) phthalate through rat milk and effects on milk composition and the mammary gland. 1987; Toxicol Appl Pharmacol 91:315-325.

Doull J, Cattley R, Elcombe C, Lake BG, Swenberg J, Wilkinson $\mathrm{C}$, Williams $\mathrm{G}$, and van Gemert $\mathrm{M}$. A cancer risk assessment of di(2-ethylhexyl)phthalate: application of the new U.S. EPA Risk Assessment Guidelines. 1999;Regul Toxicol Pharmacol 29:327-357.

Duty SM, Ackerman RM, Calafat AM, and Hauser R. Personal care product use predicts urinary concentrations of some phthalate monoesters. 2005a;Environ Health Perspect 113:1530-1535.

Duty SM, Calafat AM, Silva MJ, Ryan L, and Hauser R. Phthalate exposure and reproductive hormones in adult men. 2005b;Hum Reprod 20:604-610.

Duty SM, Silva MJ, Barr DB, Brock JW, Ryan L, Chen Z, Herrick RF, Christiani DC, and Hauser R. Phthalate exposure and human semen parameters. 2003a;Epidemiology 14:269-277.

Duty SM, Singh NP, Silva MJ, Barr DB, Brock JW, Ryan L, Herrick RF, Christiani DC, and Hauser R. The relationship between environmental exposures to phthalates and DNA damage in human sperm using the neutral comet assay. 2003b;Environ Health Perspect 111:1164-1169.

Faouzi MA, Dine T, Gressier B, Kambia K, Luyckx M, Pagniez D, Brunet C, Cazin M, Belabed A, and Cazin JC. Exposure of hemodialysis patients to di-2-ethylhexyl phthalate. 1999;Int J Pharm 180:113-121.

FDA, C. Safety Assessment of Di(2-ethylhexy)phthalate (DEHP) Released from PVC Medical Devices, U. F. a. D. A. Center for Devices and Radiological Health, ed. 2001.

Feigal D. W. FDA Public Health Notification: PVC Devices Containing the Plasticizer DEHP, U. F. a. D. A. Center for Devices and Radiological Health, ed. 2002.

Fennell, T. R., Krol, W. L., Sumner, S. C., and Snyder, R. W. (2004). Pharmacokinetics of dibutylphthalate in pregnant rats. Toxicol Sci 82, 407-418.

Foster PM, Cattley RC, and Mylchreest E. Effects of din-butyl phthalate (DBP) on male reproductive development in the rat: implications for human risk assessment. 2000; Food Chem Toxicol 38:S97-S99.
Gourlay T, Stefanou DC, Asimakopoulos G, and Taylor KM. The effect of circuit surface area on CD11b(mac-1) expression in a rat recirculation model. 2001;Artif Organs 25:475-479.

Green R, Hauser R, Calafat AM, Weuve J, Schettler T, Ringer $\mathrm{S}$, Huttner $\mathrm{K}$, and $\mathrm{Hu} \mathrm{H}$. (Use of di(2-ethylhexyl) phthalate containing medical products and urinary levles of mono(2ethylhexyl) phthalate in neonatal intensive care unit infants (National Institute of Environmental Health Sciences, National Institutes of Health, US Department of Health and Human Services). 2005.

Guzman M, Molpeceres J, Garcia F, and Aberturas MR. Preparation, characterization and in vitro drug release of polyepsilon-caprolactone and hydroxypropyl methylcellulose phthalate ketoprofen loaded microspheres. 1996; J Microencapsul 13:25-39.

Haishima Y, Matsuda R, Hayashi Y, Hasegawa C, Yagami T, and Tsuchiya T. (2004). Risk assessment of di(2-ethylhexyl) phthalate released from PVC blood circuits during hemodialysis and pump-oxygenation therapy. 2004; Int J Pharm 274:119-129.

Hauser R, Williams P, Altshul L, and Calafat AM. Evidence of interaction between polychlorinated biphenyls and phthalates in relation to human sperm motility. 2005; Environ Health Perspect 113:425-430.

Hites RA. Phthalates in the Charles and the Merrimack rivers. 1973;Environ Health Perspect 3:17-21.

Hogman CF, Eriksson L, Ericson A, and Reppucci AJ. Storage of saline-adenine-glucose-mannitol-suspended red cells in a new plastic container: polyvinylchloride plasticized with butyryln-trihexyl-citrate. 1991; Transfusion 31:26-29.

Hoppin JA, Brock JW, Davis BJ, and Baird DD. Reproducibility of urinary phthalate metabolites in first morning urine samples. 2002; Environ Health Perspect 110:515-518.

Hoppin JA, Ulmer R, and London SJ. Phthalate exposure and pulmonary function. 2004; Environ Health Perspect 112:571-574.

Jaeger RJ, Weiss AL, and Brown K. Infusion of di-2ethylhexylphthalate for neonates: a review of potential health risk. 2005; I Infus Nurs 28:54-60.

Jarfelt K, Dalgaard M, Hass U, Borch J, Jacobsen H, and Ladefoged $\mathrm{O}$. Antiandrogenic effects in male rats perinatally exposed to a mixture of di(2-ethylhexyl) phthalate and di(2ethylhexyl) adipate. 2005;Reprod Toxicol 19:505-515.

Jepsen KF, Abildtrup A, and Larsen ST. Monophthalates promote IL- 6 and IL-8 production in the human epithelial cell line A549. 2004; Toxicol In Vitro 18:265-269.

Jonsson BA, Richthoff J, Rylander L, Giwercman A, and Hagmar L. Urinary phthalate metabolites and biomarkers of reproductive function in young men. 2005;Epidemiology 16:487-493.

Jung Koo, H., and Mu Lee, B. (2005). Human monitoring of phthalates and risk assessment. 2005; J Toxicol Environ Health A 68:1379-1392.

Karle VA, Short BL, Martin GR, Bulas DI, Getson PR, Luban NL, O'Brien AM, and Rubin RJ. Extracorporeal membrane 
oxygenation exposes infants to the plasticizer, di(2-ethylhexyl) phthalate. 1997; Crit Care Med 25:696-703.

Kato K, Silva MJ, Needham LL, and Calafat AM. Determination of 16 phthalate metabolites in urine using automated sample preparation and on-line preconcentration/high-performance liquid chromatography/tandem mass spectrometry. 2005; Anal Chem 77:2985-2991.

Kavlock R, Boekelheide K, Chapin R, Cunningham M, Faustman E, Foster P, Golub M, Henderson R, Hinberg I, Little R, et al. NTP Center for the Evaluation of Risks to Human Reproduction: phthalates expert panel report on the reproductive and developmental toxicity of butyl benzyl phthalate. 2002a;Reprod Toxicol 16:453-487.

Kavlock R, Boekelheide K, Chapin R, Cunningham M, Faustman E, Foster P, Golub, M, Henderson R, Hinberg I, Little R, et al. NTP Center for the Evaluation of Risks to Human Reproduction: phthalates expert panel report on the reproductive and developmental toxicity of di-n-butyl phthalate. 2002b;Reprod Toxicol 16:489-527.

Kim IH, Park JH, Cheong IW, and Kim JH. Swelling and drug release behavior of tablets coated with aqueous hydroxypropyl methylcellulose phthalate (HPMCP) nanoparticles. 2003;J Control Release 89:225-233.

Kurahashi N, Kondo T, Omura M, Umemura T, Ma M, and Kishi R. The effects of subacute inhalation of di (2-ethylhexyl) phthalate (DEHP) on the testes of prepubertal Wistar rats.

2005; Occup Health 47:437-444.

Larsen ST, Hansen JS, Hammer M, Alarie Y, and Nielsen GD. Effects of mono-2-ethylhexyl phthalate on the respiratory tract in BALB/c mice. 2004;Hum Exp Toxicol 23:537-545.

Latini G, De Felice C, Presta G, Del Vecchio A, Paris I, Ruggieri F, and Mazzeo P. (2003). In utero exposure to di-(2ethylhexyl)phthalate and duration of human pregnancy.

2003; Environ Health Perspect 111:1783-1785.

Latini, G., De Felice, C., and Verrotti A. Plasticizers, infant nutrition and reproductive health. 2004a; Reprod Toxicol 19:27-33.

Latini G, Verrotti A, and De Felice C. DI-2-ethylhexyl phthalate and endocrine disruption: a review. 2004b;Curr Drug Targets Immune Endocr Metabol Disord 4:37-40.

Liss GM, Albro PW, Hartle RW, and Stringer WT. Urine phthalate determinations as an index of occupational exposure to phthalic anhydride and di(2-ethylhexyl)phthalate. 1985; Scand J Work Environ Health 11:381-387.

Ljungvall K, Karlsson P, Hulten F, Madej A, Norrgren L, Einarsson S, Rodriguez Martinez $\mathrm{H}$, and Magnusson U. Delayed effects on plasma concentration of testosterone and testicular morphology by intramuscular low-dose di(2-ethylhexyl) phthalate or oestradiol benzoate in the prepubertal boar. 2005; Theriogenology 64:1170-1184.

Loff S, Kabs F, Subotic U, Schaible T, Reinecke F, and Langbein M. Kinetics of diethylhexyl-phthalate extraction From polyvinylchloride-infusion lines. 2002;JPEN J Parenter Enteral Nutr 26:305-309.
Lopez Roldan P, Lopez de Alda MJ, and Barcelo D. Simultaneous determination of selected endocrine disrupters (pesticides, phenols and phthalates) in water by in-field solid-phase extraction (SPE) using the prototype PROFEXS followed by online SPE (PROSPEKT) and analysis by liquid chromatographyatmospheric pressure chemical ionisation-mass spectrometry. 2004; Anal Bioanal Chem 378:599-609.

Lovekamp Swan T and Davis BJ. Mechanisms of phthalate ester toxicity in the female reproductive system. 2003;Environ Health Perspect 111:139-145.

Luks Betlej K, Popp P, Janoszka B, and Paschke H. Solidphase microextraction of phthalates from water. 2001; J Chromatogr A 938:93-101.

Makhija SN and Vavia PR. Controlled porosity osmotic pump-based controlled release systems of pseudoephedrine. I. Cellulose acetate as a semipermeable membrane. 2003; Control Release 89:5-18.

McKee RH, Butala JH, David RM, and Gans G. NTP center for the evaluation of risks to human reproduction reports on phthalates: addressing the data gaps. 2004;Reprod Toxicol 18:1-22.

Mihovec Grdic M, Smit Z, Puntaric D, and Bosnir J. Phthalates in underground waters of the Zagreb area. 2002; Croat Med J 43:493-497.

Modigh CM, Bodin SL, Lillienberg L, Dahlman Hoglund A, Akesson B, and Axelsson G. Time to pregnancy among partners of men exposed to di(2-ethylhexyl)phthalate. 2002;Scand J Work Environ Health 28:418-428.

Moore RW, Rudy TA, Lin TM, Ko K, and Peterson RE. Abnormalities of sexual development in male rats with in utero and lactational exposure to the antiandrogenic plasticizer Di(2ethylhexyl) phthalate. 2001;Environ Health Perspect 109:229-237.

Mortensen G K, Main KM, Andersson AM, Leffers H, and Skakkebaek NE. Determination of phthalate monoesters in human milk, consumer milk, and infant formula by tandem mass spectrometry (LC-MS-MS). 2005;Anal Bioanal Chem 382:1084-1092.

Nagao T, Ohta R, Marumo H, Shindo T, Yoshimura S, and Ono H. Effect of butyl benzyl phthalate in Sprague-Dawley rats after gavage administration: a two-generation reproductive study. 2000; Reprod Toxicol 14:513-532.

O'Connor JC, Frame SR, and Ladics GS. Evaluation of a 15day screening assay using intact male rats for identifying antiandrogens. 2002; Toxicol Sci 69:92-108.

Oie, L., Hersoug, L. G., and Madsen, J. O. (1997). Residential exposure to plasticizers and its possible role in the pathogenesis of asthma. Environ Health Perspect 105, 972-978.

Petersen, J. H. (1991). Survey of di-(2-ethylhexyl)phthalate plasticizer contamination of retail Danish milks. Food Addit Contam 8, 701-705.

Rhind SM, Kyle CE, Telfer G, Duff EI, and Smith A. Alkyl phenols and diethylhexyl phthalate in tissues of sheep grazing pastures fertilized with sewage sludge or inorganic fertilizer. 2005; Environ Health Perspect 113:447-453. 
Roth B, Herkenrath P, Lehmann HJ, Ohles HD, Homig HJ, Benz Bohm G, Kreuder J, and Younossi Hartenstein A. Di-(2ethylhexyl)-phthalate as plasticizer in PVC respiratory tubing systems: indications of hazardous effects on pulmonary function in mechanically ventilated, preterm infants. 1988;Eur J Pediatr 147:41-46.

Rozati R, Reddy PP, Reddanna P, and Mujtaba R. Role of environmental estrogens in the deterioration of male factor fertility. 2002; Fertil Steril 78:1187-1194.

Saillenfait AM, Payan JP, Fabry JP, Beydon D, Langonne I, Gallissot F, and Sabate JP. Assessment of the developmental toxicity, metabolism, and placental transfer of Di-n-butyl phthalate administered to pregnant rats. 1998; Toxicol Sci 45:212-224.

Sharman M, Read WA, Castle L, and Gilbert J. Levels of di(2-ethylhexyl)phthalate and total phthalate esters in milk, cream, butter and cheese. 1994;Food Addit Contam 11:375-385.

Shimizu T, Kouketsu K, Morishima Y, Goto S, Hasegawa I, Kamiya T, Tamura Y, and Kora S. A new polyvinylchloride blood bag plasticized with less-leachable phthalate ester analogue, din-decyl phthalate, for storage of platelets. 1989; Transfusion 29:292-297.

Sjoberg P, Bondesson U, Kjellen L, Lindquist NG, Montin G, and Ploen L. Kinetics of di-(2-ethylhexyl) phthalate in immature and mature rats and effect on testis. 1985a; Acta Pharmacol Toxicol (Copenh) 56:30-37.

Sjoberg P, Bondesson U, Sedin G, and Gustafsson J. Dispositions of di- and mono-(2-ethylhexyl) phthalate in newborn infants subjected to exchange transfusions. 1985b;Eur J Clin Invest $15: 430-436$.

Sjoberg PO, Bondesson UG, Sedin EG, and Gustafsson JP. Exposure of newborn infants to plasticizers. Plasma levels of di-(2-ethylhexyl) phthalate and mono-(2-ethylhexyl) phthalate during exchange transfusion. 1985c; Transfusion 25:424-428.

Sugita T, Kawamura Y, Tanimura M, Matsuda R, Niino T, Ishibashi T, Hirabahashi N, Matsuki Y, Yamada T, and Maitani T. [Estimation of daily oral exposure to phthalates derived from soft polyvinyl chloride baby toys]. 2003.
Shokuhin Eiseigaku Zasshi 44:96-102.

Swan SH, Main KM, Liu F, Stewart SL, Kruse RL, Calafat AM, Mao CS, Redmon JB, Ternand CL, Sullivan S, and Teague JL.

Decrease in anogenital distance among male infants with prenatal phthalate exposure. 2005; Environ Health Perspect 113:1056-1061.

Swedish, E. Persistent Organic Pollutants, Monitor 16, C. Bernes, ed. (Stockholm: Swedish EPA). 1998.

Tsumura Y, Ishimitsu S, Kaihara A, Yoshii K, Nakamura Y, and Tonogai Y. Di(2-ethylhexyl) phthalate contamination of retail packed lunches caused by PVC gloves used in the preparation of foods. 2001a;Food Addit Contam 18:569-579.

Tsumura Y, Ishimitsu S, Saito I, Sakai H, Kobayashi Y, and Tonogai Y. Eleven phthalate esters and di(2-ethylhexyl) adipate in one-week duplicate diet samples obtained from hospitals and their estimated daily intake. 2001b;Food Addit Contam 18:449-460.

Walinder R, Norback D, Wessen B, and Venge P. Nasal lavage biomarkers: effects of water damage and microbial growth in an office building. 2001;Arch Environ Health 56:30-36.

Wang YB, Song L, Zhu ZP, Chen JF, and Wang XR. (2005). Effects of dibutyl phthalate on sertoli cells of rat testis.

2005;Zhonghua Yu Fang Yi Xue Za Zhi 39:179-181.

Waterman SJ, Keller LH, Trimmer GW, Freeman JJ, Nikiforov AI, Harris SB, Nicolich MJ, and McKee RH. Two-generation reproduction study in rats given di-isononyl phthalate in the diet. 2000;Reprod Toxicol 14:21-36.

Wilkinson CF and Lamb JCt. The potential health effects of phthalate esters in children's toys: a review and risk assessment. 1999;Regul Toxicol Pharmacol 30:140-155.

Wine RN, Li LH, Barnes LH, Gulati DK, and Chapin RE. Reproductive toxicity of di-n-butylphthalate in a continuous breeding protocol in Sprague-Dawley rats. 1997;Environ Health Perspect 105:102-107.

Yamashita U, Sugiura T, Yoshida Y, and Kuroda E. (2005). Effect of endocrine disrupters on macrophage functions in vitro. 2005; J UOEH 27:1-10. 